\title{
Aproveitamento dos discentes dos cursos do núcleo de ciências sociais aplicadas da fundação Universidade Federal de Rondônia/UNIR
}

\section{Use of the courses of the courses of the center of applied social sciences of the foundation Universidade Federal de Rondônia/UNIR}

\author{
Aline Maiara Silva Lima ${ }^{1}$ Gleimiria Batista da Costa Matos ${ }^{2}$ Marlene Valério dos \\ Santos Arenas ${ }^{3}$ Bruna Lívia Timbó de Araújo Balthazar ${ }^{4}$ Jackson Balthazar de Arruda \\ Câmara $^{5}$
}

\begin{abstract}
RESUMO
Esta pesquisa tem como problemática identificar as disciplinas em que, os discentes dos cursos de graduação do Núcleo de Ciências Sociais Aplicadas (NUCSA) da UNIR, possuem maiores dificuldades em alcançar a aprovação. O objetivo geral é analisar o desempenho nas disciplinas das grades curriculares dos cursos de graduação do NUCSA/UNIR das turmas ingressantes no período entre 2011 à 2014. Os objetivos específicos estão pautados em: realizar o levantamento dos discentes dos cursos de Administração, Ciências Econômicas, Ciências Contábeis, Biblioteconomia e Direito das turmas ingressantes entre 2011 à 2014; e, identificar as disciplinas que apresentam maior reprovação entre os alunos. A pesquisa constituiu-se em estudo de caso, descritivo, de abordagem mista, com levantamento de dados estruturados por meio de um estudo de corte e analisados utilizando-se de métodos de estatística descritiva. Utilizou-se ainda de pesquisa bibliográfica e análise documental. A base teórica é consubstanciada na teoria institucional combinada com o modelo de ação institucional para o sucesso acadêmico. A análise dos resultados apresentou entre as disciplinas que os alunos tem maiores dificuldades em alcançar aprovação estão as relacionadas à área de cálculo e o Trabalho de Conclusão de curso.
\end{abstract}

Palavras-chave: Ensino Superior Público; Desempenho Acadêmico; NUCSA.

\begin{abstract}
The problem of this research is to identify the disciplines in which the students of the undergraduate courses of the Nucleus of Applied Social Sciences (NUCSA) at UNIR, have greater difficulties in achieving approval. The general objective is to analyze the performance in the disciplines of the curriculum of the NUCSA/UNIR undergraduate courses of the incoming classes in the period between 2011 and 2014. The specific objectives are based on: surveying the students of the Administration, Economic Sciences courses, Accounting Sciences, Library Science and Law for incoming classes between 2011 and 2014; and, identify the subjects that show the highest failure among students. The research consisted of a descriptive, mixed-
\end{abstract}

1 Fundação Universidade Fedesral de Rondônia/UNIR. Email: aline.maia@ unir.br

2 Fundação Universidade Fedesral de Rondônia/UNIR. Email: gleimiria@ unir.br

3 Fundação Universidade Fedesral de Rondônia/UNIR. Email: marlenearenas@unir.br

4 Fundação Universidade Fedesral de Rondônia/UNIR. Email: bruna_lta@hotmail.com

5 Fundação Universidade Fedesral de Rondônia/UNIR. Email: jacksoncamara@ hotmail.com 
approach case study, with structured data collection through a cross-sectional study and analyzed using descriptive statistical methods. It was also used bibliographical research and documental analysis. The theoretical basis is embodied in institutional theory combined with the institutional action model for academic success. The analysis of the results showed that among the subjects that students have the greatest difficulty in achieving approval are those related to the area ofcalculus and the Course Conclusion Work.

Keywords: Public Higher Education; Academic achievement; NUCSA.

\section{INTRODUÇÃO}

A demanda pelo ingresso no ensino superior é crescente, no entanto o número de concluintes não acompanha proporcionalmente essa tendência. Os alunos estão ingressando no ensino superior, mas não estão concluindo os cursos.

Os dados do Censo da Educação Superior - CENSUP (INEP, 2016) demonstram a evolução do quantitativo de vagas ofertadas e de alunos ingressos e concluintes do ensino superior público federal, na modalidade de ensino presencial no período de 2006 a 2016. A partir deste censo é possível verificar que na última década, o ensino superior público expandiu tanto pela criação de novas instituições, como pela criação de novas vagas. Com relação ao ano de 2006, em 2016 o montante de vagas oferecidas cresceu $118 \%$, o de ingressantes $105 \%$ e o de concluintes $63 \%$.

Deste modo, estabelecer circunstâncias favoráveis à ampliação da permanência e acesso à educação de ensino superior, no nível de graduação, no intuito de potencializar o aproveitamento da estrutura física e de recursos humanos existentes nas universidades federais é um dos desafios enfrentados pelos gestores acadêmicos.

Na esfera pública a decisão do Tribunal de Contas da União (TCU) no 408/2002 propõe orientações para o cálculo dos indicadores de gestão visando "acompanhar a evolução de aspectos relevantes do desempenho das Instituições Federais de Ensino Superior (IFES), o que poderá indicar, ao longo dos anos, a necessidade de aperfeiçoamentos em áreas específicas, ou a correção de eventuais disfunções”.

A implementação de políticas de expansão ao acesso ao ensino superior não se mostra efetiva se as vagas ofertadas não formarem profissionais qualificados para o mercado. Conforme Lobo (2012), "de nada adianta atrair mais alunos, quando não se consegue mantê-los!".

Assim, torna-se oportuno refletir o movimento de expansão do acesso ao ensino superior e ponderar questões relacionadas ao abandono dos cursos e permanência prolongada dos acadêmicos. 
Alvarenga et. al. (2012) acreditam que, conhecendo melhor a realidade destes estudantes e os desafios enfrentados por eles, tem-se maior embasamento para discussão do assunto e avaliação de formas de se garantir a igualdade de acesso e de permanência no ensino superior a todos os estudantes.

Deste modo, os gestores acadêmicos nas universidades precisam compreender este panorama para então buscar estabelecer circunstâncias favoráveis a ampliação da permanência e sucesso no alcance da diplomação dos discentes da educação de ensino superior, no nível de graduação, no intuito de potencializar o aproveitamento da estrutura física e de recursos humanos existentes nas universidades federais.

Na educação pública, a não finalização dos cursos pelos estudantes, representa perda social, de recursos e de tempo de todos os envolvidos no processo de ensino - desde os próprios alunos, aos professores, demais servidores da instituição de ensino, o sistema de educação, e a sociedade e todo o País (LOBO, 2012).

Portanto, mais que ofertar vagas, um dos desafios enfrentados pelos gestores acadêmicos nas universidades federais é fazer com que esses alunos permaneçam na graduação durante o tempo previsto para conclusão do curso e sejam devidamente diplomados. Neste cenário, é importante que a instituição atue ativamente e busque conhecer as dificuldades enfrentadas no cumprimento da grade curricular pelos alunos, visando fazer jus aos princípios da eficiência e efetividade no cumprimento da missão institucional da universidade.

Pelo exposto, surge a questão de pesquisa desse artigo: quais as disciplinas da grade curricular, em que os discentes dos cursos de graduação do Núcleo de Ciências Sociais Aplicadas (NUCSA) da Fundação Universidade Federal de Rondônia (UNIR), possuem maior dificuldade obter êxito?

O Núcleo de Ciências Sociais Aplicadas (NUCSA) foi escolhido como objeto de estudo dessa pesquisa, e faz parte da estrutura da Fundação Universidade Federal de Rondônia (UNIR) e oferece os cursos de Administração, Biblioteconomia, Ciências Contábeis, Ciências Econômicas e Direito. Desses, apenas o curso de Direito dispõe de duas turmas por ano, com a oferta de 50 vagas por semestre, enquanto e os demais cursos disponibilizam 50 vagas anuais.

O objetivo deste artigo é analisar o desempenho nas disciplinas das grades curriculares dos cursos de graduação do Núcleo de Ciências Sociais Aplicadas (NUCSA) 
da Fundação Universidade Federal de Rondônia (UNIR) das turmas ingressantes no período entre 2011 a 2014. Os objetivos específicos estão pautados em:

1- Realizar o levantamento dos discentes dos cursos de Administração, Ciências Econômicas, Ciências Contábeis, Biblioteconomia e Direito das turmas ingressantes entre 2011 a 2014; e,

2- Identificar as disciplinas que apresentam maior reprovação entre os alunos;

$\mathrm{O}$ presente estudo justifica-se por possibilitar à instituição ter um retrato das disciplinas em que os alunos têm maior dificuldade em alcançar êxito na aprovação, permitindo a reflexão das políticas institucionais realizadas visando à atração, permanência e desempenho dos estudantes, bem como a atuação didático-pedagógica desde a atualização da metodologia de ensino, políticas de capacitação e até mesmo as formas de avaliação.

\section{FUNDAMENTAÇÃO TEÓRICA}

Nesta seção serão apresentados os pilares teórico-conceituais que irão consubstancia a presente pesquisa, apontando as teorias, modelos, conceitos essenciais para a compreensão do problema da pesquisa e atendimento dos objetivos geral e específicos do estudo.

\section{CONTEXTUALIZAÇÃO DO ENSINO SUPERIOR NO BRASIL}

A educação é direito social garantido pela Constituição Federal, e deve possibilitar o "pleno desenvolvimento da pessoa, seu preparo para o exercício da cidadania e sua qualificação para o trabalho" nos termos do art. 205 da Constituição Federal (CRFB/1988). Conforme o Plano Plurianual 2016-2019 a educação é tida como o caminho para a inclusão, redução das desigualdades sociais e a superação da pobreza, na medida em que amplia os horizontes das pessoas e abre novas oportunidades de inserção social e econômica (MPOG, 2015).

Os reflexos da educação para o desenvolvimento social e econômico de qualquer país é reconhecido pela sociedade e por seus governantes, exercendo o papel de fundamental na difusão do conhecimento. No caso do Brasil, dada suas características marcadas por grande diversidade e contrastes econômicos e sociais, a educação tem que ser prioridade para seu desenvolvimento (GEMAQUE e SOUZA, 2016). 
Entre os objetivos previstos no Programa Educação de Qualidade para todos, do Plano Plurianual 2016-2019, está à ampliação do acesso à educação superior de qualidade, em níveis de graduação e pós-graduação, considerando as especificidades da diversidade, inclusão e a aprendizagem ao longo da vida, fortalecendo a ciência, a tecnologia e a inovação (MPOG, 2015).

Nessa perspectiva, às universidades é atribuída função estratégica no desenvolvimento econômico e social do país, contribuindo para o progresso científico e tecnológico, atenuação nas desigualdades sociais, e para a geração de trabalho e renda (MEC, 2015).

As políticas públicas visando à expansão do acesso ao ensino superior fazem parte da agenda pública há algum tempo. Criado pelo decreto nº 6.096/2007, o Programa de Apoio a Planos de Reestruturação e Expansão das Universidades Federais (REUNI) tem como prioridade a expansão do acesso e a permanência ao ensino superior, por meio do aumento de vagas, redução das taxas de evasão e ocupação das vagas ociosas. O objetivo inicial do Programa era dobrar o número de alunos nos cursos de graduação em dez anos, a partir de 2008 (MEC, 2009).

Na educação superior, a prioridade é a democratização do acesso seja por meio da integração dos processos seletivos de ingresso, da adoção de cotas sociais e raciais, ampliação do número de vagas em instituições públicas, criação de novos cursos ou implementação de outras políticas que se mostrem adequadas. (MPOG, 2015).

Em pesquisa, a Associação Brasileira de Mantenedoras de Ensino Superior (ABMES), constatou que em 2015, o custo médio de um estudante de uma instituição federal foi de R\$ 20 mil (vinte mil reais), (ABMES, 2016).

Ressalta-se assim o dispêndio de todo o aparato necessário para a manutenção da atividade acadêmica - desde a estrutura física ao capital intelectual - destacando o custo que esses alunos (vagas) representam para a sociedade.

Tão sério quanto a evasão é o fato dos alunos permanecem na instituição por tempo além do previsto regularmente para finalização de seu curso, com repetências constantes, representando também um custo, implicando em gasto de recurso público superior.

MODELO DE AÇÃO INSTITUCIONAL PARA O SUCESSO DO ALUNO 
O modelo teórico proposto por Tinto e Pusser (2006) visa viabilizar a proposição de ações de natureza institucional que favoreçam o sucesso dos estudantes do ensino superior, considerando as políticas públicas, programas, práticas, contexto político e social que exerçam influência neste processo.

A persistência e sucesso do estudante ainda é, em significativa parte, um reflexo das práticas e ambiente institucionais que viabilizem o bom desempenho acadêmico (TINTO; PUSSER, 2006).

O modelo de Integração do Estudante fundamentado por Tinto (1975), pautado nos conceitos de integração moral e pertencimento coletivo, com inspiração na Teoria do Suicídio de Emile Durkheim, considera a influência da dimensão interna que é voltada para o aluno e suas experiências anteriores a graduação, características individuais e contexto familiar. Já o modelo de ação institucional prioriza as questões sob as quais a instituição possa atuar diretamente, estabelecendo cinco condições para o sucesso estudantil: compromisso institucional, expectativas institucionais, apoio ou suporte, feedback e envolvimento (TINTO; PUSSER, 2006).

O foco deste estudo está voltado para entender o sucesso do aluno, como ele pode ser influenciado pela ação institucional e as condições inerentes às universidades que são necessárias para o êxito estudantil.

Compreender o sucesso dos alunos e como ele pode ser reflexo da ação institucional implica em percebê-lo como sendo construído a partir do sucesso em uma turma de cada vez (TINTO; PUSSER, 2006). Assim, cada turma precisa ser acompanhada como sendo única e é uma parcela do todo institucional, devendo as condições de sucesso ser aplicadas a todas elas considerando suas particularidades.

O aumento das taxas institucionais de sucesso do aluno não surgem por acaso. São o resultado de um uma série de ações, políticas e práticas institucionais intencionais que são consistentemente aplicadas ao longo prazo (TINTO; PUSSER, 2006). Assim, verifica-se que os resultados dos alunos dependem de uma série de variáveis, tais como: políticas institucionais, benefícios assistenciais, formas de avaliação, metodologia, capacitação docente, acompanhamento acadêmico entre outros.

Visando definir as variáveis de cunho institucional, aquelas sobre as quais a instituição exerce controle imediato, Tinto e Pusser (2006), apresentaram em seus estudos condições de sucesso que serão a seguir conceituadas: 
"Compromisso Institucional: diz respeito ao comprometimento da instituição com o sucesso dos alunos, não bastando que esteja contemplado em planejamentos ou diretrizes, é preciso que esteja pautado na busca por incentivos, recompensas, políticas e práticas que visem melhorar os resultados alcançados pelos alunos.

Expectativas: esta condição parte da premissa de que nenhum aluno se elava a baixas expectativas. Os estudantes captam as expectativas e são influenciados pelo grau em que essas expectativas validam sua presença no campus. Essa expectativa pode ser expressa pelas regras formais e informais, estudos institucionais, compartilhamento de conhecimento e aconselhamento do alunado.

Apoio ou suporte: esse requisito subdivide-se em acadêmico, social e financeiro. $\mathrm{O}$ apoio acadêmico refere-se ao suporte por meio de grupos de estudos, tutorias, programas de apoio acadêmico; o social está relacionado à inclusão, orientação e acolhimento, senso de pertencimento, formação de centros estudantes étnicos; e o financeiro que é contemplado por políticas de assistência estudantil que proporcionem auxílio financeiro aos estudantes, visando viabilizar o custeio de suas despesas estudantis, especialmente aos estudantes de baixa renda.

Feedback: diz respeito ao monitoramento frequente do desempenho do aluno a fim de avaliar a aprendizagem, eficiência das políticas e métodos aplicados, oportunizando uma reflexão contínua tanto aos alunos como professores e gestores acadêmicos.

Envolvimento: está ligado a integração acadêmica e social do aluno. Parte do pressuposto de que quanto maior for $\mathrm{o}$ envolvimento acadêmico e social do aluno maior a probabilidade deste persistir e se formar. Abrange integração com outros estudantes, professores, institutos de pesquisa e outros atores educacionais.” 
Para os autores a integração do apoio, feedback e envolvimento influenciam na qualidade do esforço estudantil e aprendizagem dos alunos, moldando assim, o sucesso estudantil.

\section{METODOLOGIA}

Este capítulo propõe-se a evidenciar as etapas a serem seguidas na pesquisa, designando os métodos e procedimentos da pesquisa e técnicas de coleta e análise dos dados.

Trata-se de um estudo de caso, descritivo, com levantamento de dados qualitativos e quantitativos (mistos) analisados por meio de um estudo de coorte.

As pesquisas de métodos mistos utilizam a coleta e análise de dados de natureza tanto qualitativa como quantitativa, com a integração mútua das duas formas de modo sequencial, de modo que um sirva de base e apoio para a construção do outro, podendo priorizar a uma ou a ambas as formas de dados em uma ou em múltiplas fases do estudo (CRESWELL, 2013).

Quanto aos objetivos caracteriza-se como descritivo em virtude buscar descrever a situação acadêmica dos discentes e assim identificar o desempenho dos alunos nessa trajetória. Para Gil (2017, p. 26), os estudos descritivos têm como objetivo fundamental descrever determinados fenômeno.

Em um primeiro momento foi utilizada a metodologia de coorte, que tem como objeto de estudo um grupo com características comuns, a ser acompanhado por certo período de tempo. O estudo tem enfoque retrospectivo por ser elaborado com base em registros do passado com seguimento até o presente (GIL, 2017).

Foi objeto de estudo um grupo de estudantes, de turmas ingressantes entre 2011 a 2014, sendo analisado o percurso escolar destes, para verificação das disciplinas que os alunos apresentam maior dificuldade de alcançar aprovação.

Para cada disciplina da grade curricular dos cursos foram identificados os alunos aprovados; os que fizeram aproveitamento de disciplina, por cursarem em outro curso ou turma; notas não informadas no sistema; reprovados por falta; e reprovados por nota ou desempenho insuficiente. Após foram mensurados os percentuais com base na composição da turma ingressante da qual o estudante fazia parte, utilizando-se nesta etapa de estatística descritiva. 
A estatística descritiva preocupa-se com a forma pela qual podemos apresentar um conjunto de dados de forma a facilitar o entendimento de medidas estatísticas (TAVARES, 2011).

Quanto à fonte de informação, o estudo é classificado como pesquisa bibliográfica baseada em livros, artigos, periódicos sobre assunto, e, documental com base em relatórios institucionais e censo da educação superior. Para Oliveira (2007) a pesquisa bibliográfica é uma modalidade de estudo e análise de documentos de domínio científico, tais como livros, periódicos, enciclopédias, ensaios críticos, dicionários e artigos científicos.

A pesquisa documental fundamenta-se em documentos que não receberam tratamento analítico e científico (GIL, 2017). Sustenta-se na busca de informações em documentos relatório, anais, regulamentos, balancetes, comunicações organizacionais formais ou informais, filmes, fotografias, eletrônicos em geral, diários, cartas pessoais e outros (VERGARA, 2016). O presente estudo utilizou relatórios gerenciais da instituição e o censo da educação superior.

\section{RESULTADOS}

Problemas envolvendo questões voltadas para o desempenho estudantil carregam tal complexidade que não seria possível abranger todos os aspectos acerca da temática.

Assim, optou-se por investigar os cursos da área de Ciências Sociais Aplicadas da UNIR, especificamente as turmas ingressantes entre 2011 a 2014, dos curso vinculados ao NUCSA: administração, biblioteconomia, ciências contábeis, ciências econômicas e direito.

Preliminarmente, cumpre registrar os dados foram levantados com base no SINGU - Sistema de Gestão Universitária da UNIR, sendo analisado individualmente os históricos dos alunos e tabulado com uso de planilhas do Excel, visando identificar a aprovação ou não em cada disciplina.

Assim é possível vislumbrar um primeiro panorama da trajetória dos discentes das turmas ingressantes entre 2011 a 2014 que passa a ser apresentada.

\section{ANÁLISE DO DESEMPENHO ACADÊMICO}

Nesta seção, está disposto retrato do desempenho acadêmicos dos alunos por meio da análise qualitativa e quantitativa dos históricos dos discentes das 4 coortes dos cursos 
de Administração, Biblioteconomia, Ciências Contábeis e Ciências Econômicas. Para o curso de Direito, na amostra inicial foram apresentadas 8 gerações, no entanto, nesta fase da pesquisa, foram analisadas 5 coortes, mais especificamente os ingressantes dos semestres de 2011.1 à 2013.1.

Deste modo, foram analisados um total de 971 históricos para identificar a performance dos alunos em cada uma das disciplinas e assim poder detectar as disciplinas da grade curricular de cada um dos cursos em que os alunos possuem maior dificuldade. Cumpre ainda esclarecer que o campo total de cada uma das tabelas apresentadas nesta seção, representa a quantidade total de vezes que a disciplina foi cursando, ocorrendo de ser cursada mais de uma vez pelo menos aluno.

A classificação do desempenho está segmentada pelos status: aprovado, aproveitamento de disciplina, não informado, reprovado por falta e reprovado por nota.

\section{ADMINISTRAÇÃO}

No curso de Administração verificam-se na Tabela 01 as disciplinas em que os alunos apresentaram maior dificuldade no alcance da aprovação. Estão em destaque as variáveis que mais impactaram para a não aprovação dos discentes.

Tabela 1: Disciplinas com as Menores Taxa de Aprovação - Administração

\begin{tabular}{|c|c|c|c|c|c|c|}
\hline Disciplina & $\begin{array}{r}\text { Aprovado } \\
(\%)\end{array}$ & $\begin{array}{r}\text { Aproveitamento } \\
(\%)\end{array}$ & $\begin{array}{r}\text { Não } \\
\text { informado } \\
(\%)\end{array}$ & $\begin{array}{r}\text { Reprovado } \\
\text { Por falta } \\
(\%)\end{array}$ & $\begin{array}{r}\text { Reprovado } \\
\text { Por nota } \\
(\%)\end{array}$ & Total \\
\hline $\begin{array}{l}\text { Contabilidade } \\
\text { Geral II }\end{array}$ & $42 \%$ & $2 \%$ & $0 \%$ & $27 \%$ & $29 \%$ & 181 \\
\hline $\begin{array}{l}\text { Contabilidade } \\
\text { Geral I }\end{array}$ & $51 \%$ & $1 \%$ & $0 \%$ & $20 \%$ & $28 \%$ & 209 \\
\hline $\begin{array}{l}\text { Seminário } \\
\text { Integrado - } \\
\text { Trabalho De } \\
\text { Conclusão }\end{array}$ & $53 \%$ & $0 \%$ & $0 \%$ & $46 \%$ & $1 \%$ & 98 \\
\hline $\begin{array}{l}\text { Estatística } \\
\text { Aplicada A } \\
\text { Administração }\end{array}$ & $56 \%$ & $4 \%$ & $0 \%$ & $6 \%$ & $33 \%$ & 142 \\
\hline
\end{tabular}




\begin{tabular}{l|r|r|r|r|r|r|}
\hline $\begin{array}{l}\text { Introdução Ao } \\
\text { Calculo }\end{array}$ & $56 \%$ & $4 \%$ & $0 \%$ & $20 \%$ & $21 \%$ & 196 \\
\hline $\begin{array}{l}\text { Laboratório III } \\
- \text { Pratica De }\end{array}$ & $58 \%$ & $0 \%$ & $0 \%$ & $23 \%$ & $20 \%$ & 106 \\
Administração & & & & & & \\
\hline
\end{tabular}

Fonte: Elaborado pelos Autores com base nos dados do SINGU, 2018.

Assim, as disciplinas de Contabilidade Geral I e II foram as com menor nível de aprovação entre os alunos que cursaram a disciplina. A disciplina de Seminário Integrado - Trabalho de Conclusão de Curso (TCC) teve o desempenho dos alunos afetado predominantemente por reprovações por falta, ou seja, pela frequência insuficiente dos alunos na disciplina, fato esse que reflete na dificuldade que os alunos têm em apresentar o TCC.

Ademias, o que se verifica é que parcela significativa dos alunos de Administração têm dificuldades com disciplinas de cálculo e com as da área da contabilidade.

Além dessas disciplinas observou-se ainda dificuldades de alguns discentes no alcance da média na disciplina de Cálculo Aplicado à Administração, em que 22\% dos alunos dos 145 que cursaram a disciplina foram reprovados por desempenho insuficiente.

\section{BIBLIOTECONOMIA}

A Tabela 02 ilustra as disciplinas que representam os maiores entraves para os alunos do curso de Biblioteconomia no avanço da grade curricular, conforme disposto a seguir:

Tabela 2: Disciplinas com as Menores Taxa de Aprovação - Biblioteconomia

\begin{tabular}{l|r|r|r|r|r|r|}
\hline & Aprovado & Aproveitamento & informado & Reprovado & Reprovado & \\
Por falta & $(\%)$ & $(\%)$ & $(\%)$ & $(\%)$ & Total \\
Pisciplina & $(\%)$ & & & & & \\
\hline Introdução ao & & & & & & \\
Tratamento & & & & & & \\
Temático da & & & & & & \\
Informação & $52 \%$ & & & & & \\
\hline
\end{tabular}




\begin{tabular}{|c|c|c|c|c|c|c|}
\hline \multicolumn{7}{|l|}{ Projeto do } \\
\hline \multicolumn{7}{|l|}{ Trabalho de } \\
\hline \multicolumn{7}{|l|}{ Conclusão de } \\
\hline Curso (TCC) & $55 \%$ & $0 \%$ & $29 \%$ & $13 \%$ & $3 \%$ & 109 \\
\hline \multicolumn{7}{|l|}{ Introdução à } \\
\hline Informática & $55 \%$ & $3 \%$ & $25 \%$ & $17 \%$ & $0 \%$ & 219 \\
\hline \multicolumn{7}{|l|}{ Língua } \\
\hline \multicolumn{7}{|l|}{ Portuguesa: } \\
\hline \multicolumn{7}{|l|}{ Redação e } \\
\hline Expressão I & $56 \%$ & $6 \%$ & $0 \%$ & $35 \%$ & $4 \%$ & 197 \\
\hline \multicolumn{7}{|l|}{ Estatística } \\
\hline Aplicada & $57 \%$ & $3 \%$ & $22 \%$ & $9 \%$ & $9 \%$ & 184 \\
\hline \multicolumn{7}{|l|}{ Evolução do } \\
\hline \multicolumn{7}{|l|}{ Pensamento } \\
\hline \multicolumn{7}{|l|}{ Científico e } \\
\hline Filosófico & $58 \%$ & $4 \%$ & $16 \%$ & $21 \%$ & $2 \%$ & 192 \\
\hline
\end{tabular}

Fonte: Elaborado pelosAutorores com base nos dados do SINGU, 2018.

Neste curso verifica-se um cenário em que a maior parte das disciplinas com as menores taxa de aprovação se dão por conta da nota da variável não informado, que se refere ao fato da nota do discente não ter sido informada pelo professor da disciplina. Salienta-se que quando isso ocorre além do prejuízo aos alunos, causa ainda obstáculos à gestão acadêmica, visto que não é possível identificar a situação real do aluno na disciplina.

Destaca-se ainda que as disciplinas de Introdução à Ciência da Informação, História da Cultura e dos Registros e Métodos e Técnicas de Pesquisa Bibliográfica tem as taxas mais significativas de reprovação por nota, respectivamente: $28 \%, 27$ e $21 \%$ dos discentes que cursaram a disciplina não alcançaram a média para a aprovação.

\section{CIÊNCIAS CONTÁBEIS}

A performance dos discentes do curso de Ciências Contábeis pode ser observada na Tabela 03: 
Tabela 3: Disciplinas com as Menores Taxa de Aprovação - Ciências Contábeis

\begin{tabular}{|c|c|c|c|c|c|c|}
\hline Disciplina & $\begin{array}{r}\text { Aprovado } \\
(\%)\end{array}$ & $\begin{array}{r}\text { Aproveitamento } \\
(\%)\end{array}$ & $\begin{array}{r}\text { Não } \\
\text { informado } \\
(\%)\end{array}$ & $\begin{array}{r}\text { Reprovado } \\
\text { Por falta } \\
(\%)\end{array}$ & $\begin{array}{r}\text { Reprovado } \\
\text { Por nota } \\
(\%)\end{array}$ & Total \\
\hline Português & & & & & & \\
\hline Instrumental & $50 \%$ & $15 \%$ & $0 \%$ & $28 \%$ & $8 \%$ & 197 \\
\hline Contabilidade & & & & & & \\
\hline Introdutória & $51 \%$ & $9 \%$ & $0 \%$ & $26 \%$ & $15 \%$ & 203 \\
\hline Matemática & & & & & & \\
\hline Aplicada as & & & & & & \\
\hline Ciências & & & & & & \\
\hline Contábeis & $54 \%$ & $13 \%$ & $0 \%$ & $26 \%$ & $8 \%$ & 192 \\
\hline Noções & & & & & & \\
\hline Básicas De & & & & & & \\
\hline Filosofia & $61 \%$ & $17 \%$ & $0 \%$ & $22 \%$ & $1 \%$ & 181 \\
\hline Estatística & & & & & & \\
\hline Aplicada as & & & & & & \\
\hline Ciências & & & & & & \\
\hline Contábeis I & $62 \%$ & $13 \%$ & $0 \%$ & $16 \%$ & $9 \%$ & 159 \\
\hline Contabilidade & & & & & & \\
\hline Empresarial & $62 \%$ & $2 \%$ & $0 \%$ & $25 \%$ & $11 \%$ & 175 \\
\hline
\end{tabular}

Fonte: Elaborado pelos Autorores com base nos dados do SINGU, 2018.

Verifica-se que o desempenho nas disciplinas com as menores taxa de aprovação de Ciências Contábeis é reflexo de um quadro marcado pela reprovação por falta, em que os alunos se matriculam, mas não apresentam presença suficiente no decorrer do semestre.

Essa situação é combinada ainda com significativas taxas de aproveitamento como pode ser visto nas disciplinas de Português Instrumental, Matemática Aplicada as Ciências Contábeis, Noções Básicas De Filosofia e Estatística Aplicada as Ciências Contábeis I.

Pela análise qualitativa dos históricos foi possível detectar que nas disciplinas comuns a outros cursos como Português Instrumental e Noções Básicas de Filosofia que 
integram a grade do primeiro período, os alunos se matricularam nas disciplinas e por vezes no mesmo semestre ou no semestre seguinte se dava o aproveitamento.

Já para as disciplinas de Matemática Aplicada e Estatística Aplicada às Ciências Contábeis percebe-se que parcela dos alunos tem reprovações reincidentes, e recorrem a realizar a disciplina em outros cursos e posteriormente fazer o aproveitamento.

\section{CIÊNCIAS ECONÔMICAS}

O curso de Ciências Econômicas tem as disciplinas em que os alunos têm maior dificuldade de aprovação retratadas na Tabela 04, conforme pode ser visto a seguir:

Tabela 4: Disciplinas com as Menores Taxa de Aprovação - Ciências Econômicas

\begin{tabular}{|c|c|c|c|c|c|c|}
\hline Disciplina & $\begin{array}{r}\text { Aprovad } \\
\text { o (\%) }\end{array}$ & $\begin{array}{r}\text { Aproveitament } \\
\mathrm{o}(\%)\end{array}$ & $\begin{array}{r}\text { Não } \\
\text { informad } \\
\text { o (\%) }\end{array}$ & $\begin{array}{r}\text { Reprovad } \\
\text { o Por falta } \\
(\%)\end{array}$ & $\begin{array}{r}\text { Reprovad } \\
\text { o Por nota } \\
(\%)\end{array}$ & $\begin{array}{r}\text { Tota } \\
1\end{array}$ \\
\hline Monografia & $35 \%$ & $0 \%$ & $42 \%$ & $1 \%$ & $22 \%$ & 125 \\
\hline \multirow{2}{*}{\multicolumn{7}{|c|}{$\begin{array}{l}\text { Metodologia do } \\
\text { Trabalho }\end{array}$}} \\
\hline & & & & & & \\
\hline Cientifico & $54 \%$ & $8 \%$ & $6 \%$ & $25 \%$ & $8 \%$ & 171 \\
\hline Matemática I & $56 \%$ & $5 \%$ & $0 \%$ & $30 \%$ & $9 \%$ & 172 \\
\hline \multicolumn{7}{|l|}{ Teoria } \\
\hline \multicolumn{7}{|l|}{ Macroeconômic } \\
\hline a I & $57 \%$ & $2 \%$ & $0 \%$ & $28 \%$ & $12 \%$ & 121 \\
\hline \multicolumn{7}{|l|}{ Instituição } \\
\hline \multicolumn{7}{|l|}{ Direito Público } \\
\hline E Privado & $59 \%$ & $5 \%$ & $12 \%$ & $0 \%$ & $24 \%$ & 167 \\
\hline \multicolumn{7}{|l|}{ Introdução à } \\
\hline Economia & $60 \%$ & $5 \%$ & $9 \%$ & $15 \%$ & $11 \%$ & 168 \\
\hline
\end{tabular}

Fonte: Elaborado pelos Autores com base nos dados do SINGU, 2018.

Neste curso a disciplina de Monografia tem a menor taxa de aprovação entre todas as disciplinas, inclusive considerando os demais cursos, majoritariamente marcada pela não informação das notas ou situação do desempenho pelo docente. 
Esse cenário é reflexo da baixa aprovação na disciplina de Metodologia do Trabalho Científico, em que parcela dos alunos não alcançam aprovação, revelando a dificuldade dos alunos na aprendizagem das bases da metodológicas para a construção da monografia.

\section{DIREITO}

Em relação ao curso de Direito podem ser observadas Tabela 05 as disciplinas que apresentam os menores percentuais de aprovação:

Tabela 05: Disciplinas com as Menores Taxa de Aprovação - Direito

\begin{tabular}{|c|c|c|c|c|c|c|}
\hline Disciplin & $\begin{array}{l}\text { Aprovad } \\
\text { o }(\%)\end{array}$ & $\begin{array}{l}\text { Aproveitament } \\
\mathrm{o}(\%)\end{array}$ & $\begin{array}{l}\text { Não } \\
\text { informad } \\
\text { o (\%) }\end{array}$ & $\begin{array}{l}\text { Reprovad } \\
\text { o Por falta } \\
(\%)\end{array}$ & $\begin{array}{l}\text { Reprovad } \\
\text { o Por nota } \\
(\%)\end{array}$ & $\begin{array}{l}\text { Tota } \\
1\end{array}$ \\
\hline \multicolumn{7}{|l|}{ Ciência Política e } \\
\hline \multicolumn{7}{|l|}{ Teoria Geral do } \\
\hline Estado & $61 \%$ & $10 \%$ & $22 \%$ & $4 \%$ & $3 \%$ & 315 \\
\hline \multicolumn{7}{|l|}{ Direito } \\
\hline Constitucional II & $64 \%$ & $7 \%$ & $15 \%$ & $9 \%$ & $5 \%$ & 261 \\
\hline \multicolumn{7}{|l|}{ Direito } \\
\hline Internacional & $64 \%$ & $1 \%$ & $14 \%$ & $13 \%$ & $7 \%$ & 259 \\
\hline \multicolumn{7}{|l|}{ Monografia } \\
\hline II(Defesa) & $68 \%$ & $0 \%$ & $0 \%$ & $0 \%$ & $32 \%$ & 159 \\
\hline \multicolumn{7}{|l|}{ Introdução ao } \\
\hline Estudo do Direito & $69 \%$ & $12 \%$ & $5 \%$ & $12 \%$ & $3 \%$ & 285 \\
\hline \multicolumn{7}{|l|}{ Psicologia } \\
\hline \multicolumn{7}{|l|}{ Aplicada ao } \\
\hline Direito & $69 \%$ & $10 \%$ & $0 \%$ & $16 \%$ & $5 \%$ & 279 \\
\hline
\end{tabular}

Fonte: Elaborado pelos Autores com base nos dados do SINGU, 2018.

Mesmo as disciplinas com menores taxas de aprovação alcançam percentuais acima de $60 \%$, considerando ainda que parcela dos alunos nas disciplinas de Ciência Política e Teoria Geral do Estado, Introdução ao Estudo do Direito e Psicologia Aplicada 
ao Direito realizaram aproveitamento de disciplinas, que dispensa o aluno de cursar a disciplina por equivalência, o que reflete positivamente nos resultados do curso.

As disciplinas de formação básica e as introdutórias do eixo de formação profissional apresentam taxas de aproveitamento consideráveis, identificadas pela análise qualitativa feita nos históricos como ocorridas em virtude dos alunos ao ingressarem no curso já terem realizado as disciplinas anteriormente ao cursar o mesmo curso em outra instituição, ou até mesmo em outro curso nas de formação básica, visto serem conteúdos comuns a outras graduações.

É o que se observa em Ciência Política e Teoria Geral do Estado, Introdução ao Estudo do Direito, e Psicologia Aplicada ao Direito. Além das disciplinas apontadas no quadro acima, destacam-se ainda os aproveitamentos realizados em Metodologia da Pesquisa e Economia Política, representando 18\%, em ambos os casos, do total de vezes que foram cursadas.

Ocorre que os aproveitamentos, são na maior parte das vezes efetivados após o início do semestre letivo, por esta razão os alunos acabam matriculando-se na disciplina enquanto aguardam o deferimento do aproveitamento e depois de confirmado deixam de comparecer as aulas, o que reflete na taxa de reprovação por falta que pode ser observada. Fato este impede que outros alunos possam matricular-se.

Uma peculiaridade observada neste curso é o cumprimento de pré-requisitos que não é cumprido de forma rigorosa, percebendo-se diversos casos em que a exigência de pré-requisito foi dispensada, permitindo ao discente dar continuidade aos estudos de disciplina subsequentes sem o cumprimento da condição prévia estabelecida.

\section{CONSIDERAÇÕES FINAIS}

O cumprimento da missão institucional das universidades está diretamente atrelado ao alcance da diplomação dos alunos. Na esfera pública, a evasão dos alunos implica na subutilização dos recursos humanos e toda infraestrutura disponibilizada para que o serviço seja prestado. Ao ser disponibilizado um determinado número de vagas, mesmo que a maioria dos alunos abandonem seus cursos o custo da atividade será o mesmo para a sociedade.

Diante deste cenário, a presente pesquisa surgiu da inquietação quanto às disciplinas da grade curricular, em que os alunos apresentam maior dificuldades de alcançar a aprovação. 
O estudo consubstanciou-se na análise dos históricos dos alunos, de forma individual, no intuito de identificar na grade curricular dos cursos os pontos em que os alunos têm dificuldade de avançar. Entre as disciplinas com maiores dificuldades estão às relacionadas à área de cálculo, com destaque para Contabilidade, Estatística, Matemática, com exceção do curso de direito, que não contempla tais matérias em sua grade. É ainda unanimidade entre os cursos a dificuldade na aprovação das disciplinas relacionadas ao Trabalho de Conclusão de curso.

Conhecer o desempenho do aluno possibilita ao gestor acadêmico ao identificar desvios atuar junto aos discentes visando resolver as ocorrências, proporcionando assim um estreitamento na relação professor-aluno.

O acompanhamento de forma sistemática do desempenho acadêmico, constitui-se em política institucional de apoio acadêmico. Assim na pesquisa foi possível identificar de forma individual o rendimento escolar dos discentes, viabilizando aos gestores acadêmicos o acompanhamento todo o percurso acadêmico dos discente na Universidade, com o intuito de auxiliá-los a superar suas limitações, bem como potencializar suas capacidades e habilidades.

Os resultados desse monitoramento pode direcionar o gestor para quais ações adotar diante de cada caso. Pode ainda indicar a necessidade de oferta de determinadas disciplinas de forma objetiva e não meramente intuitiva.

Essa prática pode ser associada às condições para o sucesso acadêmico propostas por Tinto e Pusser (2006), mais especificamente no que se refere às expectativas, estimulando o aluno no alcance das metas estabelecidas para aprovação, com maior nível de exigência e transferindo discente a responsabilidade pela sou desempenho por meio da conscientização.

Simultaneamente, está relacionado ainda as condições para o sucesso referentes ao suporte e feedeback, pois ao passo que o monitoramento exige mais do aluno, é preciso que a instituição proporcione os meios de apoio acadêmico e feedback como instrumentos complementares nesse processo.

Foram observadas ainda disciplinas comuns aos cursos estudados em que os alunos possuem dificuldade de aprovação. Como a disciplina de Trabalho de Conclusão de curso, com registros de reprovação frequente entre os alunos dos cinco cursos. Da mesma forma as disciplinas da área de exatas, como estatística e matemática, tem as dificuldades dos alunos refletidas na reprovação em massa dos discentes. 
Verificado esse aspecto compartilhado pelos cursos, pode ser utilizada a publicação de editais conjuntos entre os departamentos, visando oferecimento dessas disciplinas em período especial.

Medidas como essa tem suporte no modelo de ação institucional para o sucesso do aluno instituído por Tinto e Pusser (2006), na condição referente ao compromisso institucional, visto que reflete uma política que reforça o comprometimento da instituição em aperfeiçoar o desempenho dos discentes em busca de melhores resultados.

Tratando-se de universidade pública, que é custeada por recursos da sociedade, é indispensável sejam adotadas medidas que viabilizem o acesso e permanência dos alunos e que os conduza no caminho da diplomação. Visto que a não conclusão dos cursos implica não somente no prejuízo econômico, mas afeta também o desenvolvimento social.

Por fim, conclui-se que o papel da universidade não tem seu fim em ofertar tão somente vagas à sociedade. É preciso que a universidade, representada pelos mais diversos atores da comunidade acadêmica estejam atendo para receber, acolher, acompanhar e direcionar os alunos em sua trajetória acadêmica.

Assim, o que se espera é os resultados apresentados oportunizem aos gestores perceberem as turmas e cada estudante de forma exclusiva e singular, que se estabeleça um vínculo mais próximo entre o estudante, o departamento do qual faz parte e com a instituição como um todo, visando estabelecer circunstâncias que conduzam os discentes ao êxito na diplomação.

\section{REFERÊNCIAS}

ALVARENGA, Carolina Faria et al. Desafios do ensino superior para estudantes de escola pública: um estudo na UFLA. Revista Pensamento Contemporâneo em Administração, v. 6, n. 1, p. 55-71, 2012.

Associação Brasileira de Mantenedoras de Ensino Superior (ABMES). A relação entre o Fies e o Ensino Superior no Brasil. 2016. Disponível em: https://abmes.org.br/noticias/detalhe/2081/estudante-de-universidade-publica-custa-89a-mais-que-aluno-fies. Acesso em: 15 mar. 2018.

BRASIL. Constituição da República Federativa do Brasil. Brasília, DF: Senado Federal, $1988 . \quad$ Disponível em: http://www.planalto.gov.br/ccivil_03/constituicao/constituicao.htm. Acesso em: 20 fev. 2018. 
CRESWELL, John W. Pesquisa de métodos mistos. 2. ed. Porto Alegre : Penso, 2013.

Fundação Universidade Federal de Rondônia / Diretoria de Planejamento, Desenvolvimento e Informação / Coordenadoria de Informação e Desempenho da (UNIR/DPDI/CID). Relatório de Gestão Anual. 2017.

GEMAQUE, Licia Santos Buhaten; SOUZA, Lúcio Gemaque. DIPLOMAÇÃO, RETENÇÃO E EVASÃO: estudo com enfoque na evasão dos cursos de graduação na Universidade Federal do Maranhão no período de 2008 a 2010 . Ensino \& Multidisciplinaridade, v. 2, n. 1, p. 84-105, 2016. Disponível em: http://www.periodicoseletronicos.ufma.br/index.php/ens-

multidisciplinaridade/article/view/4872/2983. Aceso em : 17 mar. 2018.

GIL, Antonio Carlos. Como elaborar projetos de pesquisa. 6. ed. São Paulo: Atlas, 2017.

Instituto Nacional de Estudos e Pesquisas Educacionais Anísio Teixeira (INEP). Censo da Educação Superior - Notas Estatísticas 2016. Brasília: INEP, 2017. Disponível em: . Acesso em: 15 fev. 2018.

Instituto Nacional de Estudos e Pesquisas Educacionais Anísio Teixeira (INEP). Sinopse Estatística da Educação Superior 2015. Brasília: INEP, 2016. Disponível em: http://portal.inep.gov.br/web/guest/sinopses-estatisticas-da-educacao-superior. Acesso em: 20 jan. 2018.

LOBO, Maria Beatriz de Carvalho Melo. Panorama da evasão no ensino superior brasileiro: aspectos gerais das causas e soluções. Associação Brasileira de Mantenedoras de Ensino Superior. Cadernos, n. 25, 2012. Disponível em: http://www.institutolobo.org.br/imagens/pdf/artigos/art_087.pdf. Acesso em: 05 mar. 2018.

Ministério da Educação. Relatório de Gestão Consolidado do Exercício de 2014. Brasília, 2015.2 Disponível em: https://contas.tcu.gov.br/egestao/ObterDocumentoSisdoc?codPapelTramitavel=5285835 5. Acesso em: 09 jan. 2018.

Ministério da Educação/Secretaria de Articulação com os Sistemas de Ensino (MEC/ SASE). Planejando a Próxima Década Conhecendo as 20 Metas do Plano Nacional de Educação. 2014. Disponível em: . Acesso em: 21 fev. 2018.

Ministério da Educação. Programa de Apoio a Planos de Reestruturação e Expansão das Universidades Federais - Relatório de primeiro ano. 2009. Disponível em: $=$. Acesso em: 09 jan. 2018 .

Ministério do Planejamento, Orçamento e Gestão (MPOG). Plano Plurianual 20162019. Brasília, 2015. Disponível em: http://www.planejamento.gov.br/secretarias/upload/arquivo/spi-1/ppa-2016-2019/ppa2016-2019-ascom-3-1.pdf/view. Acesso em: 22 fev. 2018. 
TAVARES, Marcelo. Estatística aplicada à administração. Florianópolis: Departamento de Ciências da Administração / UFSC; [Brasília]: CAPES: UAB, 2011. Disponível em: http://www.cesadufs.com.br/ORBI/public/uploadCatalago/10481013042012Estatistica_ Aplicada_a_Administracao_Aula_1.pdf. Acesso em: 30 de mar. 2018.

TINTO, Vincent; PUSSER, Brian. Moving from theory to action: Building a model of institutional action for student success. National Postsecondary Education Cooperative, p. 1-51, 2006. Disponível em: https://web.ewu.edu/groups/academicaffairs/IR/NPEC_5_Tinto_Pusser_Report.pdf. Acesso em: 02 mar. 2018.

Tribunal de Contas da União - TCU / Secretaria Federal de Controle Interno - SFC. Orientações para o cálculo dos indicadores de gestão: decisão TCU no 408/2002 plenário. Disponível em: . Acesso em: 15 dez. 2017.

VERGARA, Sylvia Constant. Projetos e relatórios de pesquisa em administração. 16. São Paulo: Atlas, 2016. 